\title{
Commentary
}

\section{DIN Technical Report 133 - Toxicological Evaluation of Additives for Tobacco Products - A Guide}

\author{
Anja Thielen \\ Verband der Cigarettenindustrie, Neustädtische Kirchstraße 8, 10117 Berlin, Germany
}

The regulations of tobacco additives in the USA and the member states of the European Union show considerable diversity. One rationale for regulation is based on the results of toxicological testing. Currently, no international, European or national standards exist for toxicity testing of additives in tobacco products.

In 2001, the European Parliament adopted Directive 2001/37/EC concerning the harmonization of the regulation of tobacco products in the member states of the European Union (Directive 2001/37/EC of the European Parliament and of the Council of 5 June 2001 on the approximation of the laws, regulations and administrative provisions of the Member States concerning the manufacture, presentation and sale of tobacco products). Specifically, the Directive requires the disclosure of additives in tobacco products and their toxicological data. The national implementation of the Directive in Germany was the reason for the development of a Guide by the DIN Working Group "Toxicology of Additives".

DIN is the German Institute of Standardization (Deutsches Institut für Normung) and has been recognized by the German government as the national standards body. The Institute represents German interests at the international and European level.

The Working Group “Toxicology of Additives”, established in 2002, consists of six members of the industry, independent scientific institutions and regulatory bodies. The Group compiled basic material for toxicological methods and investigated under which conditions existing methods are applicable to tobacco products.

As a result, the "DIN Technical Report 133 - Toxicological Evaluation of Additives for Tobacco Products - A Guide" was published in 2004 in German and in 2005 in English $(1,2)$. It presents an overview of the present knowledge in this field and proposes a testing strategy. The Guide is regarded as a basis for the development of future technical regulations.
The Working Group takes the view that the testing of additives should be as practice-oriented as possible. Accordingly, the testing of additives should be carried out in burned form in a tobacco matrix. The Group gives preference to principle-based testing of the additives in a reference cigarette rather than to a product-based strategy with actual marketed brands as test objects. For a pragmatic approach, the ingredients should be tested as single substances if applied in higher concentrations, e.g., $>1 \%$ in cigarette tobacco, and as mixtures when used only in smaller amounts, e.g., ppm range.

In the Guide, the use of mainstream smoke generated by a smoking machine according to standard smoking procedures as defined by DIN/ISO/FTC is proposed as a test agent.

There is a wide range of possibilities under which conditions mainstream smoke can be used as a "test agent". The Group gives preference to fresh native mainstream smoke as a test agent due to its closeness to the real-life situation. Testing with different "surrogates" is regarded as justifiable as long as the important biological properties to be tested are not lost.

The known chemical properties of smoke components and their toxicological potency (initiators, radicals, oxidants, co-carcinogens, cytotoxic substances, etc.) are the basis for the proposed test strategy. The following set of in vitro assays for tobacco smoke is recommended: bacterial mutagenicity tests, cytotoxicity tests (for example: neutral red uptake) and genotoxicity tests (for example: micronuclei formation), the latter two with mammalian cells. This basic test battery should be complemented by a set of screening tests for biochemical reactivities ( $\mathrm{SH}$-index, radical index, oxidative potential) and the chemical determination of the so-called "Hoffmann Analytes" (45 toxicologically relevant smoke constituents).

At the moment, it is uncertain how valid are the three basic tests. Only minor changes (both increase and decrease) in 
some smoke components were observed when cigarettes with and without additives were compared. The biological responses in the different test systems were not significantly different among the various experimental cigarettes $(3,4)$. However, the three basic in vitro tests are well-established methods and are available for timely regulation of tobacco products.

In this context, it should be mentioned that in December 2004 Health Canada established the three basic tests as a requirement for the Canadian tobacco industry. A working group of the Cooperation Centre for Scientific Research Relative to Tobacco (CORESTA) recommended the same basic test battery for toxicity testing of tobacco products. It remains to be seen whether the proposals in the DIN report will be adopted, modified, rejected or extended by other scientific or regulatory organisations.

\section{REFERENCES}

1. DIN-Fachbericht 133: Toxikologische Bewertung von Zusatzstoffen für Tabakprodukte - Ein Leitfaden; Beuth Verlag GmbH, Bestellnummer: 97615 (2004).

2. DIN-Fachbericht 133: Toxicological evaluation of additives for tobacco products - A guide; Beuth Verlag GmbH, Bestellnummer: 97615 (2005).

3. Baker, R.R., E.D. Massey, and G. Smith: An overview of the effects of tobacco ingredients on smoke chemistry and toxicity; Food. Chem. Toxicol. 42 Suppl. (2004) 58-83.

4. Carmines, E.L.: Evaluation of the potential effects of ingredients added to cigarettes. Part 1: Cigarette design, testing approach, and review of results; Food Chem. Toxicol. 40 (2002) 77-91. 